

Cuadernos de $\mathrm{H}$ ideas

ISSN: 2313-9048

cuadernosdehideas@perio.unlp.edu.ar

Universidad Nacional de La Plata

Argentina

\title{
A última guerra pela Colônia do Sacramento (1777)
}

Possamai, Paulo Cesar

A última guerra pela Colônia do Sacramento (1777)

Cuadernos de H ideas, vol. 14, núm. 14, 2020

Universidad Nacional de La Plata, Argentina

DOI: https://doi.org/10.24215/23139048e035 


\title{
A última guerra pela Colônia do Sacramento (1777)
}

\author{
The last war for the Colony of Sacramento (1777) \\ Paulo Cesar Possamai \\ Universidade Federal de Pelotas, Brasil \\ paulocpossamai@gmail.com
}

DOI: https://doi.org/10.24215/23139048e035

\section{Resumo:}

Em 1774 os portugueses reconquistaram o Rio Grande de São Pedro, que estava na mão dos espanhóis desde 1762, desencadeando uma resposta dos espanhóis que organizaram uma grande ofensiva militar. Sob o comando de D. Pedro de Cevallos, nomeado vice-rei do Rio da Prata, uma frota espanhola tomou a ilha de Santa Catarina e a Colônia do Sacramento em 1777. A mudança do governo em Portugal, com a morte de do rei José I levou a um acordo com a Espanha que resultou num tratado de paz que deteu a ofensiva espanhola e resultou na devolução da ilha de Santa Catarina aos portugueses, porém a Colônia do Sacramento foi definitivamente cedida à corte de Madrid.

Palavras-chave: Guerra, Diplomacia, Colonização.

\section{Abstract:}

In 1774 the Portuguese reconquered the Rio Grande de Sao Pedro, which had been in Spanish hands since 1762, triggering a response from the Spanish who organized a major military offensive. Under the command of D. Pedro de Cevallos, appointed Viceroy of the River Plate, a Spanish fleet seized the island of Santa Catarina and the Colonia del Sacramento in 1777. The change of government in Portugal, with the death of King José I led to an agreement with Spain that resulted in a peace treaty that halted the Spanish offensive and resulted in the return of the island of Santa Catarina to the Portuguese, but the Colony of Sacramento was definitely ceded to the court of Madrid.

KEYWORDS: War, Diplomacy, Colonization.

\section{A última guerra pela Colônia do Sacramento (1777)}

A Colônia do Sacramento foi fundada na margem esquerda do Rio da Prata em 1680 por D. Manuel Lobo, obedecendo ao plano do príncipe regente D. Pedro de expandir os domínios portugueses na América, a fim de assegurar vantagens territoriais e econômicas à Coroa portuguesa. A ocasião era propícia, pois a decadente Espanha de Carlos II, o último Habsburgo espanhol, não parecia capaz de opor resistência aos velhos projetos expansionistas portugueses que visavam dominar o estuário platino e, através dele, assegurar a manutenção do fluxo da prata contrabandeada das minas de Potosí para Lisboa por via dos portos brasileiros.

Porém, se a metrópole espanhola estava enfraquecida, a isolada fortaleza de D. Manuel Lobo não pôde resistir ao ataque combinado das forças coloniais espanholas e dos exércitos indígenas das missóes jesuíticas, grupos para os quais a presença portuguesa no Prata constituía uma grande ameaça. A destruição de Colônia, levada a cabo oito meses após sua fundação, levou o príncipe regente a, sob ameaça de guerra, forçar a Coroa espanhola a restituir-lhe a posse do território de Sacramento, através do Tratado Provisional de 1681.

Foram bastante difíceis os primeiros anos que se seguiram ao restabelecimento dos portugueses em Colônia em 1683, quando as restrições do governo de Buenos Aires, que procuravam impedir o contrabando e a exploração do gado selvagem que abundava nos campos da margem norte do Rio da Prata, se somaram à corrupção generalizada que marcou o governo de Cristóvão Ornelas de Abreu (1683-1689). A situação melhorou sensivelmente sob as administrações de Francisco Naper de Lencastre (1689-1699) e de seu sucessor, Sebastião da Veiga Cabral (1699-1705), com o incremento da política de povoamento e a intensa exploração das riquezas pecuárias do atual território uruguaio. Porém, a Guerra da Sucessão 
Espanhola colocaria Portugal e Espanha em campos opostos na Europa, resultando no desencadeamento das hostilidades no Prata e no abandono de Colônia às forças de Buenos Aires em 1705.

A guerra terminou com a assinatura dos tratados de Utrecht, nos quais Filipe $\mathrm{V}$ teve de fazer várias concessões a fim de obter o reconhecimento das nações europeias à ascensão dos Bourbons ao trono espanhol. O tratado de paz com Portugal, assinado em 1715, assegurou aos portugueses a devolução do território da Colônia do Sacramento. A partir de então, a Coroa portuguesa iniciou uma verdadeira política de povoamento na região, através do envio de sessenta casais da província de Trás-os-Montes. A retomada do contrabando garantiu a remessa de grandes quantidades de prata, ao passo que a exploração do gado selvagem trouxe como consequência a luta com os espanhóis e indígenas pelo domínio do território, marcando a fase mais próspera e dinâmica da história da Colônia do Sacramento.

Se os primeiros tempos ainda foram difíceis devido aos problemas de abastecimento que marcaram o governo de Manuel Gomes Barbosa (1716-1722), a situação mudaria radicalmente com a chegada do seu sucessor. A junção do apoio decidido da Coroa à grande capacidade administrativa do governador Antônio Pedro de Vasconcelos (1722-1749) foram os fatores responsáveis por um período de grande desenvolvimento que pode ser considerado como o apogeu da presença portuguesa no Rio da Prata.

Porém, a prosperidade dos habitantes da Colônia do Sacramento preocupava a Coroa espanhola, lesada pelo intenso contrabando, enquanto os colonos e os índios das missóes conviviam a contragosto com a concorrência portuguesa na exploração do gado selvagem. Um incidente diplomático em Madri, sem maiores consequências na Europa, forneceu aos espanhóis um motivo para tentar desalojar os portugueses do Prata, dando início ao cerco de Colônia, que se estendeu de outubro de 1735 a setembro de 1737 . O envio de reforços e expedições navais conseguiu impedir a retomada de Sacramento, mas não teve sucesso em romper o cerco espanhol, que foi mantido após o armistício, marcando o fim da crescente expansão portuguesa pelo interior do território.

O sítio de 1735 marca, portanto, o início de uma nova fase na história de Sacramento. Depois da assinatura do armistício em 1737 e, particularmente, durante o reinado de Fernando VI (1746-1759), que foi marcado pela reaproximação das Coroas ibéricas, o contrabando voltou a florescer, mas a exploração da riqueza pecuária fez-se antes através da cooperação com os indígenas e espanhóis que da presença efetiva dos portugueses no pampa. Também acabou a expansão agrícola, uma vez que a manutenção do campo de bloqueio impediu a criação de novas quintas nas terras fora do controle dos portugueses.

Embora o Tratado de Madri, em 1750, estipulasse a troca da Colônia do Sacramento pelos Sete Povos das Missões, ela jamais foi efetivada, sendo que o Tratado de El Pardo, de 1761, anulou o anterior. A guerra voltaria ao Prata como consequência do conflito europeu que opôs os Bourbons à maior parte das demais nações europeias, entre as quais Portugal. No contexto da Guerra dos Sete Anos, o governador do Rio da Prata, D. Pedro de Cevallos, conquistou Colônia em 1762 e o Rio Grande de São Pedro no ano seguinte. Pelo Tratado de Paris a Espanha foi obrigada a devolver Colônia a Portugal mas se recusou a devolver o Rio Grande, sob a alegação de que a fortificação fora feita pelos portugueses em terras pertencentes à Coroa espanhola.

Em 1766 os luso-brasileiros tentaram recuperar o Rio Grande. Embora a tentativa tenha sido frustrada, eles conseguiram apoderar-se da margem norte do canal que liga a Laguna dos Patos com o Atlântico. Do povoado do Norte, rebatizado com o nome de São José do Norte em homenagem ao rei de Portugal, partiu uma nova ofensiva contra o Rio Grande nos anos de 1773 e 1774. Dessa vez somaram-se às tropas locais grandes contingentes de homens recrutados no Brasil e em Portugal que lutaram sob o comando do general Henrique Böhn (Bento, 1996).

A presença de um forte contingente militar próximo ao Rio da Prata amedrontou os súditos do rei da Espanha. Numa carta ao Secretário de Estado, escrita em 29 de dezembro de 1776, o governador de Colônia informava que em Buenos Aires só havia cem soldados pagos e que a cidade "se achava em grande desassossego e temor", temendo uma invasão portuguesa. ${ }^{1}$ De fato, no ano anterior o governador do Rio da Prata, Juan 
José de Vértiz, havia pedido à Coroa que não lhe enviasse novos soldados pois não tinha recursos para mantêlos (Sierra, 1981).

Por sua vez, a situação da Colônia do Sacramento também não era muito confortável, já que se encontrava fortemente cercada pelo campo de bloqueio imposto pelos espanhóis em 1735 e que fora reforçado em 1762. Francisco Millau, na sua Descripción del Río de la Plata, de 1772, nos conta como então se encontrava a Colônia do Sacramento.

"La salida de esa angostura para la Campaña está enteramente cerrada a los Portugueses con una fuerte palizada que llega de una a otra ensenada hasta el agua. Hay siempre de guardia en este cordón un destacamento de tropa, que hace parte de un cuerpo grande de la guarnición de Buenos Aires, que se halla acampado en una altura a media legua poco menos de Colonia, con el fin de mantener un continuo bloqueo a esa Ciudad"2

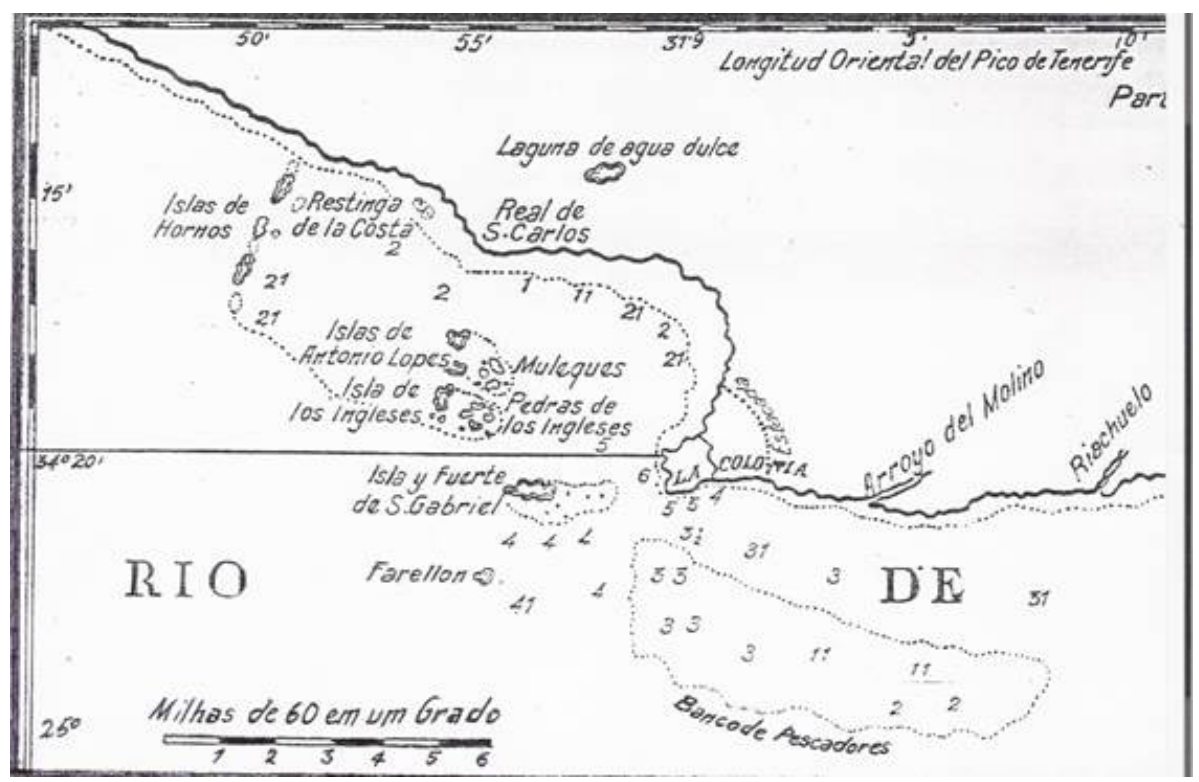

Figura 1

Detalhe do Plano de la Plaza de la Colonia del Sacramento, Don Tomás Lopez, 1777.

Fuente: Monteiro, J. C. R. (1937). A Colônia do Sacramento, 1680-1777. Porto Alegre: Livraria do Globo.

A Espanha respondeu à ofensiva portuguesa com recrutamentos realizados em várias províncias da Península para os postos de soldado e marinheiro. Uma frota partiu de Cádiz em 13 de novembro de 1776 sob o comando de D. Pedro de Cevallos, nomeado vice-rei do Rio da Prata, levando mais de onze mil e quinhentos homens a bordo. Em fevereiro do ano seguinte a esquadra aportou na ilha de Santa Catarina, onde as guarnições das fortalezas que defendiam a ilha abandonaram suas posições e buscaram refúgio no continente, de onde iniciaram as tratativas de rendição. Cevallos exigiu a capitulação incondicional e quando a frota espanhola seguiu para o Rio da Prata levou consigo 523 soldados portugueses na condição de prisioneiros de guerra (Flores, 2004).

Fortes temporais dividiram a esquadra na altura do Rio Grande de São Pedro, impedindo a sua reconquista por Cevallos que seguiu para o sul, chegando em Maldonado em 19 de abril, de onde logo passou a Montevidéu. Ainda quando se encontrava em Santa Catarina, o vice-rei do Rio da Prata recebeu a notícia da morte do rei de Portugal, D. José I, e pensando que um acordo entre as Coroas ibéricas pudesse frustrar sua ofensiva, de imediato partiu para a conquista da Colônia do Sacramento. O governador de Colônia, coronel Francisco José da Rocha, não tinha como sustentar a praça sem reforços, pois anteriormente havia enviado parte das suas tropas para auxiliar a reconquista do Rio Grande e a frota espanhola lhe impedia a comunicação com o Rio de Janeiro. As poucas embarcações que tentaram romper o bloqueio foram capturadas e o confisco da correspondência informou Cevallos sobre a posição crítica em que se encontrava José da Rocha (Sierra, 1981). 
Os espanhóis apressaram-se em se fortificar ao redor de Colônia e mostrar seu poderio através de algumas investidas contra a fortaleza. O governador português reuniu então o conselho de guerra, perante o qual assumiu a responsabilidade pela entrega da praça, garantido pela ordem secreta passada pelo marquês de Pombal de render-se depois de simular sua defesa por algum tempo (Monteiro, 1937).

Segundo um diário espanhol, em 4 de junho o marechal D. Victorio de Navia tomou posse de Colônia em nome do rei da Espanha. No dia seguinte Cevalhos e suas tropas entraram na praça, instalando-se na casa do governador. Se seguiram uma missa com Te Deum na igreja matriz e salvas de artilharia das fortificações e da frota. Nesse mesmo dia partiram rumo a Buenos Aires oito embarcações conduzindo os prisioneiros de guerra. No dia sete se iniciou o desmantelamento das muralhas. ${ }^{3}$

Um dos poucos testemunhos que temos sobre a tomada de Sacramento em 1777 foi escrito pelo padre Pedro Pereira Fernandes de Mesquita, vigário da Vara e capeláo do regimento de cavalaria (Rupert, 1994). Nesse documento o sacerdote procurou salvar a honra de Francisco José da Rocha dizendo que "determinou o governador render a praça, antes que seus defensores e habitadores perecessem à fome [...] e talvez poderia assim tirar do inimigo algumas condições mais vantajosas” (Mesquita, P. 1868:351).

Outros documentos que encontramos a esse respeito são duas cartas do governador da Colônia do Sacramento escritas enquanto ele se encontrava em Buenos Aires, em 1778. Na primeira carta, na qual explicou o motivo da rendição, o governador escreveu que "uma praça que não tem mantimentos é pelas leis militares prisioneira de guerra e se lhe não concedem capitulações se não a beneplácito do conquistador" (da Rocha, J. 1876:284)

Segundo o relato do padre Mesquita, no começo do sítio, o coronel atestou que a quantidade de alimentos disponíveis só podia alimentar a tropa por cinco dias. Entre os habitantes também não se achou muita coisa, pois como há oito meses não chegavam embarcações de comércio todos viviam às custas dos armazéns reais. O governador sabia que Cevallos tinha conhecimento da falta de víveres em que se achava por haver interceptado as suas cartas.

Porém, quando o governador iniciou as tratativas para a capitulação, o vice-rei do Rio da Prata não aceitou as suas condições mas lhe assegurou as mesmas que tinha dado ao governador de Santa Catarina. Seguimos então a descrição que nos dá o padre Mesquita do dia em que os portugueses abandonaram Colônia:

"No dia 3 de junho se formou toda a guarnição desarmada no meio da praça com suas mochilas às costas; foram saindo pela porta da campanha, regando o caminho com lágrimas, por entre duas alas que formou a tropa espanhola, desde a porta até a praia, e ali os foram embarcando para bordo de alguns navios, que tinham prontos para isso, e os conduziram a Buenos Aires [...] Em 25 de junho saíram os oficiais com suas famílias e alguns particulares, que à força do dinheiro o alcançaram, em quatro embarcações, que lhes sinalou, e no dia seguinte [Cevallos] mandou fixar editais que se aprontassem todos os portugueses sem exceção de pessoa para que se transportassem a Buenos Aires" ${ }^{4}$

Embora os oficiais estivessem livres para retirarem-se aos domínios portugueses, o governador da Colônia do Sacramento seguiu para Buenos Aires com seus soldados, evitando embarcar para o Rio de Janeiro, onde poderia ser castigado pela rendição da praça apesar das ordens recebidas nesse sentido. Alegava que seguia o destino da tropa para "animar os soldados a não perderem a esperança de serem restituídos, pois, sem a sua presença, eles se veriam obrigados a casar, povoando [a Espanha] com eles as suas terras" (da Rocha, J. 1876:293)

Ao libertar os oficiais portugueses, D. Pedro de Cevallos escreveu ao vice-rei do Brasil pedindo-lhe que fizesse o mesmo com os três oficiais espanhóis que seguiam prisioneiros dos lusitanos: "Todia [sic] los tiene V.E. en su Jurisdicción, padeciendo muchas vejaciones, según me han informado, por cuios motivos podía yo con mas razón embiar á los oficiales Portugueses Prisioneros de Guerra, á Parages remotos de los Dominios del Rey mi amo". 5

A população civil também tinha a liberdade de se retirar mas foi embarcada às pressas para Buenos Aires sob o pretexto de que de lá poderia dirigir-se para os domínios da Coroa de Portugal. Na carta em que se defendia de ter rendido a praça antes de conseguir melhores termos de capitulação o governador alegou que se Cevalhos 
"dava liberdade de saírem os moradores que quisessem, era mera política, porque evitaria todo o modo de [o] poderem fazer" (da Rocha, J. 1876:315) Sobre o deslocamento para o outro lado do rio retomamos o relato do padre Mesquita:

"Foram-se embarcando todos os portugueses com o que puderam levar; e querendo muitos fretar embarcações para serem transportados à sua custa, prevendo que no transporte haviam [de] ser roubados (como sucedeu), poucos puderam alcançar esse indulto [...] mandando-os embarcar atropeladamente deixaram a maior parte dos seus móveis, e os [bens] que levavam para os navios eram logo injustamente roubados pelos marinheiros; e o que deles escapara servia logo de presa no desembarque em Buenos Aires" 6

O governador de Colônia confirmou o relato do padre sobre a pobreza dos deportados ao escrever que teve que vender seus bens a fim de sustentar a sua família "e acudir a muitos portugueses e portuguesas que, uns por não terem, outros por terem sido roubados pelos marinheiros espanhóis se acham sem ter [o] que comer" (da Rocha, J. 1876:294)

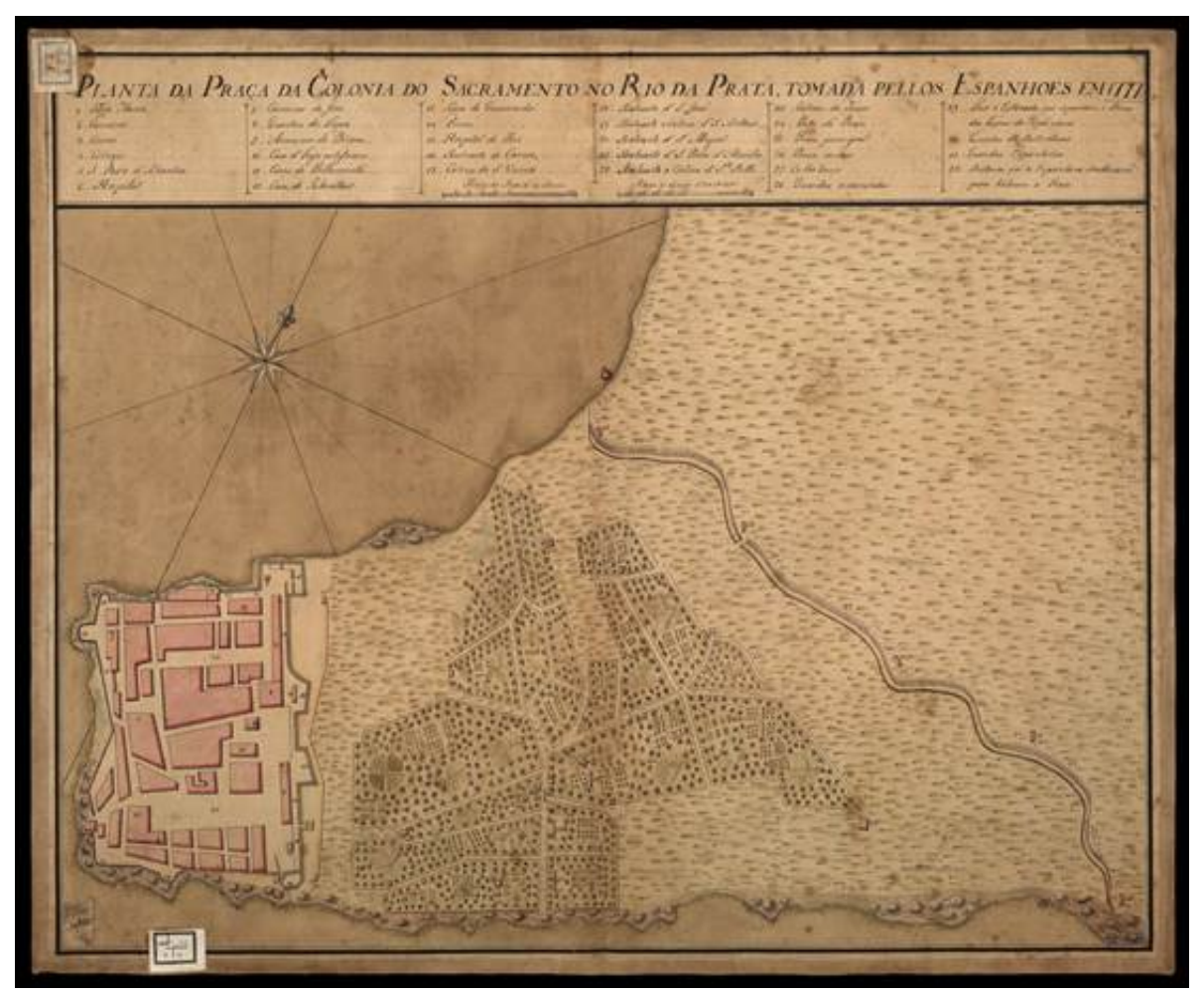

Figura 2

"Planta da Colônia do Sacramento no Rio da Prata tomada pelos espanhóis em 1777" Biblioteca Nacional (Brasil) ${ }^{7}$

Em Buenos Aires, os luso-brasileiros foram reunidos na praça de São Nicolau, onde foram embarcados em carretas rumo a seus destinos: mais de trinta famílias foram para enviadas a Luján enquanto outras seguiram para Areco, Arrecifes e Pergamino. Segundo Mesquita "desta forma pretendia D. Pedro Cevallos povoar as fronteiras com vassalos alheios, sem despesa do seu soberano, e mandando ordens aos comandantes daquelas paragens que lhes repartissem terras para edificarem e plantarem" (Mesquita, P. 1868:359).

No mesmo lugar, os portugueses tiveram que se desfazer dos seus escravos e dos bens que não conseguiram embarcar nas carretas pelos valores que lhes davam os compradores, num processo que nosso cronista chamou de "roubo". Alguns tentaram escapar, mas não foram poupados pelo tenente-rei que organizava a expedição dos moradores de Colônia para o interior. 
"Uma viúva que no mesmo sítio lhe suplicou [que] a dispensasse do desterro, por ter uma filha e uma sobrinha donzelas sem homem algum que lhes servisse de abrigo, respondeu em altas vozes na mesma praça: que fosse para onde era mandada que tão viúva seria lá como em Buenos Aires; que se Jesus Cristo fosse português não escaparia a ser desterrado" 8

Ainda segundo o padre Mesquita, os portugueses de Pergamino eram tratados como escravos pelo seu comandante. Alguns conseguiram fugir para Buenos Aires enquanto outros subornavam os oficiais com a mesma intenção. Porém, na capital, as autoridades mandaram prender os fugitivos e remetê-los de volta aos seus assentamentos, "mas quando as carretas chegaram a Recoleta [...] já iam vazias, porque foram os pobres dando as roupas que tinham sobre si aos condutores" (Mesquita, P. 1868:360).

Os soldados, por sua vez, foram enviados para mais longe. Os prisioneiros feitos em Santa Catarina e os que foram aprisionados nas embarcações foram mandados para Mendoza. Os soldados de Colônia foram enviados a Córdoba, onde ficaram instalados no antigo colégio dos jesuítas. Receberam do governador local rações de carne por algum tempo até que foram expulsos e tiveram que buscar sustento por si próprios.

Provavelmente o relato do padre Mesquita tende a exagerar as privações passadas pelos portugueses com o intuito de que a Coroa lusitana intercedesse pelos seus súditos e pagasse pelas perdas e maus tratos dos deportados, como era costume pedir depois de uma guerra. Ele fez repetidas queixas de que os prisioneiros foram roubados pelos espanhóis em várias etapas, o que nos leva a crer que mais que serem despossuídos de tudo que tinham, eram obrigados a pagar por cada favor que lhes era prestado. As queixas sobre a apropriação dos escravos dos portugueses por parte dos espanhóis também parecerem refletir uma preocupação constante do autor do relato.

Ainda segundo o padre Mesquita: "Estas e outras desumanidades com que tratam os portugueses as julgam os castelhanos por coisa muito lícita e necessária, porque, como já disse, somos reputados por eles mais vis e infames que os judeus ${ }^{9}$ e qualquer coisa que lhes faz um português a reputam como sacrilégio" (Mesquita, P. 1868:361). Contudo, o mesmo demonstrou seu preconceito contra os espanhóis justificando que os prisioneiros inimigos eram obrigados a trabalhar nas fortificações do Rio de Janeiro, onde deveriam ficar reclusos 10 "para não darem exercícios àquelas más artes que todos professam, [as] quais são os roubos e a borracharia” (Mesquita, P. 1868:361). Um cronista anônimo do sítio vivido pela Colônia do Sacramento entre 1735 e 1737 também relacionou os espanhóis à embriaguez, referindo-se aos seus "antigos e costumados vocábulos de pícaros borrachos" (Possamai, 2018:78).

O coronel Francisco José da Rocha se manteve em Buenos Aires até agosto 1778, quando pediu ao sucessor de D. Pedro de Cevallos no governo do vice-reino do Rio da Prata, D. Juan José de Vértiz y Salcedo, condução para ele e os habitantes da Colônia do Sacramento que ainda se achavam na cidade para o Brasil. Pedia ajuda com transportes e víveres até Maldonado, de onde seguiram por terra ao Rio Grande. Embora muitos soldados já se tivessem dispersado pela América espanhola, tendo esse caminho facilitado pelos espanhóis, segundo o ex-governador de Colônia, os que ficaram obtiveram a ajuda do vice-rei para voltar (Mesquita, 1868). Ao desembarcar no Rio de Janeiro, acusado pelos oficiais pela rendição da praça, José da Rocha foi preso e enviado a Lisboa onde foi julgado e condenado à morte. Porém a sentença comutada em degredo perpétuo para Angola, onde veio a falecer (Monteiro, 1937).

Em carta de 29 de abril de 1780 o vice-rei do Rio da Prata informou que mandou uma ordem circular em doze de agosto de 1778 a todos os lugares onde se encontrassem portugueses para que se lhes auxiliasse no seu retorno aos domínios da Coroa de Portugal. Em 25 de setembro escreveu ao governador de Tucumán e ao corregedor de Cuyo para que obrigassem a saída dos portugueses existentes nos seus distritos, auxiliando-os a seguir para Buenos Aires por conta da Fazenda Real. E para que ninguém ignorasse essa providência publicou bandos em janeiro e em fevereiro de 1779, ordenando que os portugueses recebessem auxílio para partir. Em busca dos subsídios para o deslocamento inscreveram-se até alguns dos portugueses que ficaram nos domínios espanhóis depois a conquista de Colônia em 1762, porém o vice-rei negou auxílio para eles alegando que: 
"El único reparo que se ofreció en este particular lo ocasionaron algunos habitantes Portugueses que en vez de retirarse después de las discordias de 1762 se domiciliaron en esta Ciudad y casaron con naturales de ella. Quisieron después salir de aquí con mujer, hijos y esclavos, y aun alguno solicitaba a su cuñada, comprendida en su familia. Me negué consentir en ello haciéndome cargo de la despoblación que causaría este permiso y del inconveniente que resultaba pasar a Dominio extraño muchos que habían nacidos Vasallos del Rey". ${ }^{11}$

O vice-rei também negou aos portugueses de San Carlos, na Banda Oriental, a pretensão de retiraremse levando consigo dez bois por família e três cavalos por pessoa. O pedido foi negado com base nas leis de Castela e das Índias, que proibiam a transferência de cavalos e vacas de uma província a outra. Porém permitiu aos portugueses que vendessem seu gado antes de saírem dos domínios espanhóis.

Quanto ao pagamento das cargas dos navios apresados durante a última guerra, dizia que não tinha como fazê-lo por falta de inventários. Informava que os escravos tomados em Santa Catarina haviam sido devolvidos embora houvesse divergência quanto ao seu número, pois o vice-rei do Brasil dizia que eram 49 e o comissionado para isso dizia que eram 40. Também já havia sido devolvida a artilharia portuguesa que se encontrava em Buenos Aires e Montevidéu, além do produto de algumas presas feitas pelos navios corsários que atuaram no Rio da Prata contra os navios mercantes portugueses.

Por sua vez, em 7 de maio de 1779, o governador do Rio Grande de São Pedro, José Marcelino de Figueiredo, escreveu ao vice-rei do Brasil que não tinha recursos para atender ao grande número de famílias que chegava da Colônia do Sacramento "vindos pobres e arrastados, e me pedem de comer, e casas pela Fazenda Real, porém, nem eu tenho [o] que lhes dar nem sei o que deles deva fazer" (Monteiro, J. 1979:337).

Segundo Rego Monteiro: "Fez o general o que pôde, dividiu os rincões de Cristóvão Pereira de Abreu e da Torotoma em datas de terra de quarto de légua em quadro, localizando neles 51 famílias em cada um" (Monteiro, J. 1979:337). Em setembro o governador fez nova distribuição de terras pois era grande o número de famílias acampadas na vila do Rio Grande. A pedido dos imigrantes repartiu terras nos campos do canal de São Gonçalo, onde pretendia criar uma freguesia com a transferência de um pároco que assistia nas proximidades de Viamão, não conseguindo porém cumprir seu intento.

Reencontramos nosso cronista da rendição da Colônia do Sacramento, o padre Pedro Pereira Fernandes de Mesquita, como vigário da paróquia do Rio Grande de São Pedro onde interessou-se, como o governador, em criar uma nova freguesia nas terras ocupadas pelas famílias vindas de Colônia e das Ilhas. Além de motivos religiosos e políticos, propósitos econômicos também motivaram os moradores a pedir a criação de uma nova paróquia, pois a ida dos trabalhadores para Rio Grande na quaresma, quando eram mais necessários na matança do gado, prejudicava a produtividade das charqueadas que iam prosperando na região. Em outubro de 1809, um grupo de moradores, dentre os quais o padre Mesquita, escreveu ao Príncipe Regente sobre a necessidade da criação de uma nova paróquia nas margens da Laguna dos Patos. Por fim, em 1812, foi criada a freguesia de São Francisco de Paula, núcleo da atual cidade de Pelotas, um dos principais centros urbanos do estado do Rio Grande do Sul (Moreira, 1994).

\section{REFERÊNCIAS}

Bento, C. (1996). A Guerra da Restauração. Rio de Janeiro: Biblioteca do Exército Editora.

Carta de Francisco José da Rocha, Buenos Aires, 20 de março de 1778. Revista do Instituto Histórico e Geográfico Brasileiro, 1876, tomo 39, parte II.

Diario de las providencias dadas para el sitio de la Colonia, su ataque y rendición. Mayo-Junio de 1777. (1941). Campaña del Brasil, Antecedentes Coloniales. Buenos Aires: Archivo General de la Nación, tomo III.

Flores, M. B. R. (2004). Os espanhóis conquistam a ilha de Santa Catarina, 1777. Florianópolis: Editora da UFSC.

Martínez Crespo, J. (2007). A guerra na Galicia do Antigo Réxime. Noia: Toxosoutos.

Mesquita, P. P. F. (1868). Relação da conquista de Colônia escrita em Buenos Aires em 1778. Revista do Instituto Histórico e Geográfico Brasileiro. Rio de Janeiro, tomo 31, parte I 
Millau, F. (1947). Descripción del Río de la Plata. Buenos Aires - México: Espasa - Calpe.

Monteiro, J. C. R. (1937). A Colônia do Sacramento, 1680-1777. Porto Alegre: Livraria do Globo.

Monteiro, J. C. R. (1979). A dominação espanhola no Rio Grande do Sul (1763-1777). Anais do Simpósio Comemorativo do Bicentenário da Restauração do Rio Grande. Rio de Janeiro: Instituto Histórico e Geográfico Brasileiro, Instituto de Geografia e História Militar do Brasil, tomo IV.

Moreira, A. P. (1994). Primórdios de Pelotas (Freguesia e tempos que a precederam). Revista do Instituto Histórico e Geográfico de Pelotas, 1(1), 1-19.

Possamai, P. (2018). Diário do Sítio da Colônia do Sacramento (1734-1737). Porto Alegre: Editora Fi.

Reitano, E. (2010) La inmigración antes de la inmigración. Mar del Plata: EUDEM.

Rupert, A. (1994). História da Igreja no Rio Grande do Sul. Porto Alegre: EDIPUCRS.

Sierra, V. D. (1981). Historia de la Argentina. Buenos Aires: Editorial Cientifica Argentina, tomo II.

\section{Notas}

1 Ofício do [governador da Nova Colônia do Sacramento] Francisco José da Rocha ao [secretário de estado da Marinha e Ultramar, Martinho Melo de Castro] sobre o socorro prestado a embarcações e o atraso nas chegadas destas, com mantimentos enviados à Colônia. Arquivo Histórico Ultramarino: AHU_ACL_CU_012, Cx. 7, D. 620.

2 Millau, F. (1947). Descripción del Rio de la Plata. Buenos Aires - México: Espasa - Calpe, p. 112

3 Diario de las providencias dadas para el sitio de la Colonia, su ataque y rendición. Mayo-Junio de 1777. (1941). Campaña del Brasil, Antecedentes Coloniales. Buenos Aires: Archivo General de la Nación, tomo III, p. 473.

4 Mesquita, P. P. F. (1868). Relação da conquista de Colônia escrita em Buenos Aires em 1778, p. 353

5 Carta de Cevallos ao Marquês do Lavradio. Colônia, 20 de junho de 1777. Campaña del Brasil, Antecedentes Coloniales. Buenos Aires: Archivo General de la Nación, tomo III, p. 474.

6 Mesquita, P. P. F. Op Cit, p. 355

7 Biblioteca Nacional, Brasil. ARC.025,02,026 - Cartografia. http://objdigital.bn.br/acervo_digital/div_cartografia/ca rt511933.jp

8 Mesquita, P. P. F. Op Cit, p. 358

9 "En algunos casos ser portugués no solo generaba desconfianza respecto a la pureza de sangre, también resultaba, para algunos, sinónimo de ladrón y estafador, o la sola mención de la palabra en concepto de insulto". Reitano, E. (2010) La inmigración antes de la inmigración. Mar del Plata: EUDEM, p. 166.

10 Numa carta de 3 de abril de 1778 um marinheiro galego descreveu seu cativeiro no Rio de Janeiro: "Todos nos escupen en cara [...] llevamos paciensia ya que Dios hasí lo manda; nos embarcaron en sus Barcos y nos dieron a comer una comida que bomitan los gatos, feyxóns negros con azeyte y carne seca con Arina de palo que muchos días has que que fuymos entrando nos moriamos de hambre [...] Y Bos madre, sumamente amada pidyreis a Dios y a su madre soberana que salgamos con bien de entre estos Yndios portugueses..." Martínez Crespo, J. A guerra na Galicia do Antigo Réxime. Noia: Toxosoutos, p. 106.

11 Ofício do conde de Fernán Nuñes ao [secretário de estado dos Negócios Estrangeiros] Aires de Sá e Melo sobre a situação dos portugueses prisioneiros ou emigrantes e acerca da restituição das posses e bens da Nova Colônia do Sacramento, conforme estabelecido nos tratados. Arquivo Histórico Ultramarino: AHU_ACL_CU_012, Cx. 7, D. 647. 